\title{
Prevention of Childhood Anxiety Disorders
}

\author{
Sarosh Khalid-Khan \\ Dept of Psychiatry \\ Division of Child and adolescent Psychaitry \\ Queen's University, Kingston, Ontario \\ Canada
}

\section{Introduction}

Anxiety disorders consist of excessive and frequent worrying which causes physical and mental distress and impairment in overall functioning (NIH\&SAMHSA, 1999). Anxiety disorders are the most common mental health problems reported by children, adolescents and adults (Costello, Angold, \& Burns, 1996; Goodman, Ford, Richards, Gatward, \& Melzer, 2000; Kessler et al., 2005; Muris, Merckelbach, Mayer, \& Prins, 2000). The prevalence of childhood anxiety disorders ranges from $10 \%$ to $22 \%$ (Dadds, Spence, Holland, Barrett, \& Laurens, 1997.) with lifetime prevalence estimated to be about 28.8\% (Kessler et al., 2005) with ages of onset between 10 to 12 years (Kessler et al, 2005). About one in 6 children have anxiety that causes impairment in their daily lives (Dadds, Spence, Holland, Barrett, \& Laurens, 1997). There are many sequelae of anxiety disorders including an elevated risk for later development of mood disorders, other anxiety disorders, substance use as well as physical health concerns (Kessler et al., 2005). In addition, anxiety disorders can result in much psychosocial suffering including higher rates of dropping out of school, lower income levels, difficulties in intimate relationships and difficulty keeping one's employment (Beidel \& Turner, 1998; LeFauve et al., 2004; Lewinsohn \& Clarke, 1999; Pine, Cohen, Gurley, Brook, \& Ma, 1998; Schatzberg, Samson, \& Rothschild, 1998; Woodward \& Fergusson, 2001).

In addition to the impairment and suffering experienced by children and adolescents, there is a significant cost associated with anxiety disorders. It is estimated that the United States spends more than $\$ 42$ billion a year on anxiety disorders (Greenberg et al, 1999). In a 2009 Status Report, the Canadian Pediatric Society indicated that mental health problems continue to grow among children and youth and are predicted to increase by $50 \%$ by the year 2020 (Children's Mental Health Ontario Pre-Budget Submission 2010). However, three out of four children who need specialized services do not receive them as access to mental health services continues to be insufficient and in some cases declining (Children's Mental Health Ontario Pre-Budget Submission, 2010). In clinics, waiting lists are long and no-show and attrition rates sometimes are over 50\% (Weist et al,1999). Many children who do receive clinical intervention fail to respond (Barrett, Dadds, \& Rapee, 1996; Donovan \& Spence, 2000; Weisz et al., 1997) or experience recurrence of symptoms despite receiving treatment (Last et al., 1996). Yet, treating mental health issues in children and youth in a timely way prevent excessive health care costs and ensure productive lives (Children's Mental Health Ontario Pre-Budget Submission, 2010). 
Anxiety disorders are diagnosed in children and adolescents if they begin to interfere in normal daily functioning in three domains i.e. home, school and with peers. Anxiety disorders are listed under the following headings: generalized anxiety disorder, separation anxiety disorder, social anxiety disorder, specific phobia, panic disorder, obsessive-compulsive disorder and post-traumatic stress disorder (DSM-IV, 2000). There are no definitive biological or psychological tests for anxiety disorders and diagnoses are made clinically based on information from multiple sources i.e.teachers, parents or other caregivers in other settings. Anxiety disorders in children often first manifest as physiological symptoms and are misinterpreted as physical illness. Stomach aches are a common physical manifestation of anxiety in younger children. Some young children may manifest temper tantrums when in fact they are having panic attacks. In adolescents headaches mixed in with nausea and stomach aches are more common. These physical symptoms often result in avoidance behavior which often manifests as school refusal. Behaviors resulting from anxiety such as school refusal and temper tantrums are viewed as oppositionality. Due to the avoidance as the end result of anxiety disorders, they are often unrecognized and hence untreated in children. Moreover, these children are usually perfectionistic and want to please so they further go unnoticed especially in a classroom setting. On the other hand, children with disruptive behavior disorders are noticed more and thus are more frequently referred for treatment (Compton et al, 2004, In-Albon \& Schneider, 2007).

Currently, the most effective treatment available for anxiety disorders are cognitivebehavioral therapy (CBT) and antidepressant medications specifically the serotonin reuptake inhibitors (SSRIs). Both treatments alone are empirically supported options. For mild to moderate symptoms, usually CBT is offered first. For moderate to severe symptoms, a combination of CBT and SSRI is often helpful. Families, in general, prefer nonmedical or psychosocial interventions at initial evaluation (Walker et al, 2001). However, often CBT therapists are in short supply (Andrews et al, 2002).

\section{Prevention}

Due to these concerns, it seems logical to move toward services that provide prevention of anxiety disorders. The benefits of prevention are that a large number of people can be targeted over a short period of time, it is more cost effective and there is reduced distress for children due to earlier intervention (Lowry-Webster, 2001). Preventive mental health programs serve two purposes. From a health care perspective, they address and identify risk and protective factors in individuals, providing for better long-term prognoses. In addition, these programs accrue economic benefits because prevention is often less expensive than the economic and societal costs once an illness has manifested (Beardslee et al, 2011).

For implementation of prevention programs, it is important to consider the risk factors, protective factors and strategies for prevention. There is a complex interplay of biological, psychological and environmental factors in the development of childhood anxiety disorders (Donovan et al, 2000). In the development of childhood anxiety the following risk factors have been implicated.

\section{Risks and protective factors in childhood anxiety disorders}

Puberty results in maturational changes not only physically but also emotionally. Puberty may increase risk factors for many psychiatric disorders including anxiety disorders. 
According to Leen-Feldner et al, adolescents with advanced pubertal status and greater reactivity to a hyperventilation challenge were at increased risk for panic symptoms (LeenFeldner et al, 2007).

Fear conditioning is known to be linked to the genesis of anxiety. In a study by Otto et al, 2007), risk factors for fear conditioning were examined in a nonclinical sample. Those in the sample that had higher levels of anxiety sensitivity (increased anxiety symptoms) predicted increased tendency towards fear conditioning (Otto et al,2007).

The quality of attachment between an infant and the primary caregiver is an important indicator of future development of anxiety disorders (Erickson et al, 1985; Lewis et al, 1984; Sroufe et al, 1990). In a study by Warren et al,1997, the role of attachment style on the later development of anxiety disorders was studied in 172 children at 12 months and then later at 17.5 years of age. At 12 months a pattern of anxious resistant attachment predicted later anxiety disorders, even after controlling for infant temperament and maternal anxiety.

Parental anxiety is a risk factor for childhood anxiety disorders both through the mechanism of heritability and parent's modeling of anxious behaviors (Rosenbaum et al., 1988; Turner et al, 1987; Weissman et al, 1984). It is estimated that heritability accounts for about $40-50 \%$ of anxiety symptoms in children (Thapar et al, 1995).

Behavioral inhibition has been identified by Kagan et al( Kagan et al, 1989; Kagan et al, 1991)as a stable temperament style consisting of shyness and elevated physiological arousal having a strong genetic component (DiLalla et al, 1994; Plomin et al, 1989). Children with behavior inhibition are more likely to develop an anxiety disorder (Biederman et al, 1993; Kagan, 1997; Rosenbaum et al, 1993).

Other risk factors for childhood anxiety disorders are traumatic and stressful life events following which children have higher levels of fears. Higher rates of anxiety disorders are present in children following major natural disasters (Dollinger et al, 1984). Moreover, parenting behaviors have been identified to interact with other risk factors in the development of childhood anxiety. Parents of anxious children often model, prompt, and reinforce anxious behavior in their children (Barrett et al, 1996). Other parental characteristics that contribute to risk factors for childhood anxiety are being overly controlling, critical and, overprotective (Krohne et al, 1991).

Protective factors either promote positive development or protect against risk factors. A person's temperament, cognitive ability and social competence can all serve as protective factors against developing anxiety disorders (Farrell et al, 2007). Other protective factors include parental monitoring of child's behaviors (Jessor et al., 1995), peers and adults in a child's life who are good role models (Hawkins et al, 1992) and acceptance and support by peers (Jessor et al, 1991; Quinton et al., 1993). In addition, a positive connection with the school with parental monitoring in both school and home setting and parents' having a positive relationship with the school (Greenberg et al, 2001) all contribute towards protection from risks of anxiety disorders. Lastly, the type of responses children use to cope with stressful experiences influence how much anxiety and distress they experience (Spence et al, 2001).

\section{Prevention strategies}

In the past few years school personnel have become interested in programming to address the social and emotional needs of children due to the resultant deleterious effects of difficulties in these areas on their academic and social functioning. In this regard, there has 
been a shift to implement evidence-based psychosocial treatments in schools in a preventative fashion (Miller et al, 2010). Recent governmental policy initiatives are requiring the implementation of evidence-based treatments in schools (Robertson, David \& Rao, 2003). Schools are an important and dominant component of children's environment both for their academic and social learning. Having a classroom intervention by teachers and school counselors makes it easier to identify children suffering from anxiety. Teachers have unlimited access to children in their classroom and know their strengths and weaknesses well. It is not only cost-effective for teachers to provide the intervention to students but students can learn from peers and share their experiences with them thus providing support (Miller et al, 2010).

Individual cognitive behavioral therapy has been studied for childhood anxiety disorders and is effective for $70 \%$ for clinically referred children (In-Albon \& Schneider, 2007). Groupbased CBT has been adapted recently and researched as a school-based intervention (Barrett \& Turner, 2001; Masia, Klein, Storch \& Corda, 2001; Stallard, Simpson, Anderson, Hibbert \& Osborn, 2007). The recent challenge for many researchers has been to study the successful implementation of these studies into a community or school setting. These studies have the challenge of following the treatment but being flexible to a real-world setting.

The Committee on Prevention of Mental Disorders (Mrazek et al, 1994) describes a continuum of interventions going from prevention at one end and treatment at the other end. The following are three main forms of prevention: universal, targeted or selective, and indicated. A universal preventive approaches are either designed to enhance resilience in all children (i.e. an entire grade or school population) or improve mental health regardless of risk and avoids the need for screening. Other universal programs are targeted at a specific disorder. These programs are more readily accepted because they are proactive, emphasizing positive coping skills and provided to everyone thus avoiding any possibility of stigmatization though labeling. Under the targeted programs, selective programs are for children who are at increased risk of developing disorders and involves screening. Indicated programs also require screening and are for individuals with minimal symptoms who do not meet diagnostic criteria for any disorder. Treatment programs target children with a diagnosed condition (Lowry-Webster et al, 2001). In this paper both the universal and targeted school-based anxiety prevention programs will be reviewed.

\section{Universal prevention strategies}

A study by Hains (Hains et al, 1992) examined the effectiveness of two cognitive-behavioral interventions to help adolescent boys cope with stress and other negative emotions. The project was described to all sophomores and juniors and those who were interested were invited to attend an orientation meeting. Twenty-five adolescent boys ages 15-16 year old were randomly assigned to either a group receiving cognitive restructuring or to a second group receiving anxiety management training. Both these groups were compared to a wait-list control group on measures of anxiety, anger, self-esteem, depression, and reports of anxious self-statements. Both the intervention groups showed significant decline in levels of anxiety, expression of anger, and depression. These treatment gains were maintained at an 11-week follow-up.

The FRIENDS program (Barrett et al, 2004) is a universal preventive program for both anxiety and depression with increasing evidence base and support from World Health Organization (World Health Organization, 2004). The FRIENDS program (acronym for 
F=Feelings; R=Relax and feel good; I=I can do it! I can try my best!; E=Explore solutions and coping step plans; N=Now reward yourself! You've done your best!; $D=D o n ' t$ forget to practice; $S=S m i l e !$ Stay calm for life!) consists of 10 weekly session and 2 booster sessions. This program is tailored for different developmental levels with a CBT protocol adapted from Phil Kendall's "The Coping Cat" (Kendall, 1994).. There are 2-4 parent sessions teaching parents coping strategies for their own anxiety, reinforcement strategies, contingency management and problem-solving and communications skills. The FRIENDS program has been validated as an effective prevention program for child and youth anxiety and depression (Dadds et al, 1997; Barrett et al, 2000; Lowry-Webster et al, 2001; LowryWebster et al, 2003; Lock et al, 2003).

Barrett et al (2000, 2001) evaluated a "train-the-trainer" model of intervention in children ages 9-10 years in grade 6. Children with internalizing symptoms were assigned to either an intervention led by a psychologist, a teacher or a control condition with a standard curriculum. The FRIENDS 12-session program was implemented as a curriculum in the classroom by training the teachers and psychologists. There were four sessions for parents. At the end, children reported considerable decrease in anxiety symptoms in either intervention by a psychologist or a teacher.

Lowry-Webster et al (2001) studied the effectiveness of the FRIENDS universal program for prevention of anxiety in 594 students aged 10-13 years randomized to either a control or an intervention condition. Both groups reported significant decrease in anxiety and the decline was significantly greater in the intervention group regardless of their risk status. A follow up study after one year by Lowry-Webster et al (2003) showed that results were maintained with the intervention group having lower scores on anxiety self-report measures. Eightyfive per cent of children in the intervention group who were scoring above the clinical cutoff for anxiety and depression were symptom free in the intervention condition compared to $31.2 \%$ in the control group.

In a study of universal prevention with 733 children enrolled in grade 6 (ages 9-10) and grade 9 (ages 14-16), Lock et al, 2003 studied children from 7 different socioeconomic school settings. The children were assigned randomly to a FRIENDS intervention program or a control condition of a standard curriculum. Students completed self-rating measures. Students who were "high risk" based on high scores on anxiety measures were given a structured diagnostic interview. Results showed a general decrease in anxiety scores which were significant for students in the intervention group at the end of the program and at 1 year follow up. This study also showed that children in Grade 6 had higher levels of anxiety before intervention but post-intervention had greater reductions in anxiety and depression at 12 month follow up compared to grade 9 children. In addition, there was a delayed effect in improvement of depression symptoms that was apparent only at the 1 year follow up. In addition, girls tended to have higher levels of anxiety than boys and girls in Grade 6 were more responsive to the intervention than Grade 9 girls.

Barrett et al (2006) evaluated the above mentioned study by Lock et al for its long term effectiveness at 36 months. The decrease in scores due to the intervention were maintained in grade 6 but not for children in grade 9 emphasizing the fact that intervention in grade 6 might be an optimal time for decreasing risk for anxiety. There were significantly fewer high-risk students at 36-month follow-up in the intervention condition than in the control condition proving the durability of prevention effects for children in Grade 6. The outcomes were noticeable for up to 3years following a brief 
cognitive behavioral intervention delivered by teachers within the school. For girls who had the highest anxiety and showed the biggest decline after one year, the preventive effect lasted for only 24 months.

The FRIENDS program was implemented in the UK in a school setting by Stallard et al (2007) and its effectiveness was examined. The program was delivered by school nurses to 10-11 year olds in one urban and 2 rural schools. The school nurses were supported by teachers and teacher's assistants. This was non-randomized study in which 106 children received the program. The children were assessed 6 months before the program, at the start of the program and 3 months after the program. Results showed that the levels of anxiety and self-esteem were stable 6 months before the program. Three months after the completion of the program, anxiety had significantly decreased and self-esteem had increased. Children with the most severe emotional problems benefited from the program. The study is limited by its small sample size, short follow-up and the single cohort design. The study by Miller et al (2010) modified a locally developed CBT intervention program, Taming Worry Dragons (TWD; Garland \& Clark, 2000). In a public elementary school, 118 children were randomly assigned either to an 8-week intervention or to a wait-list control. Teachers were trained in a full-day workshop by a licensed psychologist. The teachers then implemented the TWD program to all the children in the randomized treatment arm. The results showed no significant differences between the two groups and that the manualized CBT intervention did not reduce symptoms of anxiety in either self-reports or parent reports of anxiety symptoms in the general school population. The study cited its limitations as having a small sample size, absence of screening for co-morbid disorders and lack of follow-up.

\section{Targeted prevention strategies}

Early intervention and prevention programs can be more cost-effective in reducing the burden of illness of childhood disorders. To effectively conduct an early intervention program there should be a reliable way to screen children at risk, an access point to identify these at-risk children., and a cost-effective intervention program (Dadds, Spence, 1997).

The Queensland Early Intervention and Prevention of Anxiety Project (Dadds et al, 1997), an indicated prevention program in Australia, targeted 1,786 children ages 7-14 years to evaluate the effectiveness of a cognitive-behavioral and family-based group intervention (using the Coping Koala: Prevention Manual) for preventing the onset and development of anxiety problems in children. All the children were screened for anxiety symptoms using children self-reports and asking teachers to nominate children in their class who displayed the most anxiety. After screening, 128 children were assigned to a 10-week school-based child and parent-focused psychosocial intervention or a control group. The children received weekly 1-2 hour cognitive-behavioral sessions delivered by psychologists. The parents attended 3 child management training sessions. After completion of the program, both groups showed improvements. At six-month follow-up, the improvement in the intervention group was maintained. This group received follow up at 12 months and at 2 years (Dadds et al, 1999). At 12 months, both the intervention and the control group converged, however, at 2-year follow-up the group receiving the intervention was again superior to the control group. This study is an example of an indicated intervention targeted towards individuals who already show early signs or 
low levels of a disorder. Because the interventions are targeted only towards those at greatest risk, (Offord et al, 1998) they are more cost-effective and can be provided to only those who need it.

The above study was conducted by psychologists. To assess the effectiveness of an indicated early intervention and prevention program for anxiety disorders when conducted by school staff, Hunt et al, (2009) conducted a randomized controlled trial. A total of 1120 children in their first year of high school were recruited from 19 schools. Students who were at risk for the development of an anxiety disorder ( 1 standard deviation above the average score based on an age-related normative sample) were screened and identified. Teachers were asked to nominate 3 students with increased anxiety and subsequently 24 students were added to the study. Nine schools were randomly assigned to the control condition $(n=137)$, and 10 to the intervention condition $(n=260)$. A total of 260 students were entered in the study. The FRIENDS program was implemented in each school by a school counselor assisted by a support teacher both of whom attended a 2-day training workshop. The program was run within school hours. The students completed assessments at 2- and at 4year follow-up. No differences in outcomes were found between intervention and control groups. There was little difference between conditions at the 2 year and 4 year follow up on self-reported symptoms. This study replicated the Queensland Early Intervention and Prevention Project (Dadds et al, 1997) with a few changes. The intervention was delivered by school counselors and teachers instead of psychologist, there was assessment of treatment fidelity and a long-term follow-up was added. This study highlights the challenges of delivering a school-based program effectively by school staff.

Because of the potential role of withdrawn or inhibited temperament as an important risk factor for later development of anxiety disorders, some researchers have focused on very young age groups. It is difficult to differentiate in this age group between temperament and disorder since these can be overlapping but are also distinct constructs (Rapee \& Spence, 2004; Turner et al., 1996). It is possible that some of these children with inhibited temperament already meet criteria for an anxiety disorder and thus could qualify for assignment to either selective or indicated intervention (Mrazek \& Haggerty, 1994). The following studies highlight the selective treatment programs.

LaFreniere \& Capuano (1997) identified 43 anxious and withdrawn preschoolers, ages 31-70 months. These preschoolers were randomly assigned to either intervention or control condition. Over the next 6 months, the intervention group received 11 home visits which included child interaction skills, providing parent education and improving parenting skills and improving social support. The study showed significant difference between the intervention group and the control group with the intervention group showing improved social competence and less maternal control. In this study, however, levels of anxiety or withdrawn behavior, which was the main variable, did not differ significantly between the groups.

Rapee et al (2005) conducted an early intervention program to prevent the development of anxiety in preschool children. Withdrawn or inhibited behavior, which is one of the best identified risk factors for later anxiety disorders, was the main selection criteria for children in the program after a lab assessment. The participants who were 146 inhibited children (ages 3-5 years) and their parents were randomly assigned to either a parenteducation group $(n=73)$ or a control group $(n=73)$. Parent education was conducted in groups of 6 sets of parents with mothers more frequently attending the groups. Parents received a total of 6 sessions which were 90 minutes each and were weekly for the first 
four sessions, then one session 2 weeks later and the last session one month after that. This program was group based and brief for ease of applicability and transportability. Results showed that children with parents in the intervention group at 12 months showed a significantly greater decrease in anxiety compared to the waitlist control group but no significant changes were seen on measures of inhibition/withdrawal. In fact, both groups showed decreases in measures of inhibition so the effects of parent intervention on inhibition could not be demonstrated.

The same group of children and their parents were assessed by Rapee et al (2010) at 3 years $(n=121)$ as they were entering middle childhood. Diagnostic interviews and questionnaires were repeated at 12, 24 and 36 months. Laboratory observations were repeated only at 12 and 24 months. Results showed that children whose parents received the intervention had lower levels of anxiety symptoms according to parents' and child reports. No significant changes were noted on levels of inhibition.

Contrary to the above two studies, the study by Kennedy et al (2009) not only showed greater reductions in anxiety disorders but also showed greater reductions in parent and laboratory observed measures of behavioral inhibition. Participants in this study were 71 children aged 36-58 months and their parents who were randomly assigned to either a parent intervention $(n=35)$ or a 6 -month waitlist $(n=36)$. Children were included if they met the following two criteria: they had a high score for behavioral inhibition on lab assessment and one of their parent met DSM-IV criteria for an anxiety disorder. The parent intervention was delivered in a group format with sets of 6 parents in the group. The program consisted of 8 sessions lasting 90 minutes each with a phone call after a month of the last session. Sessions consisted of psychoeducation, parent management strategies for anxious children, development of graded hierarchies, cognitive restructuring for both parents and children, exposure for parents' fears, coping plans, maintenance and relapse prevention, reinforcement of progress and trouble shooting.

An example of a selective prevention trial is the one by Balle et al (2010). This study focuses on Anxiety Sensitivity as an early risk factor for the development of anxiety disorders. The aim of this study was to assess the efficacy of a brief school-based selective prevention program for anxiety in children and adolescents with high levels of anxiety sensitivity. Children and adolescents $n=613$ aged $11-17$ years of age from 4 schools were screened. Children with over $80^{\text {th }}$ percentile in the Children Anxiety Sensitivity Index but with no current psychiatric disorder or treatment $(n=130)$ were offered the study but 105 accepted participation in the study. Out of the 105 participants, 92 entered the trial. The rest were excluded on the basis of meeting criteria for a psychiatric disorder. These 92 participants were randomly assigned to either the prevention group $(n=47)$, waitlist control $(n=45)$ and a third normal control group. Both groups showed a significant decrease in all outcome variables but there was no differences between the prevention or the waitlist group. Differences emerged in the six-month follow-up with greater anxiety sensitivity reductions in the prevention group compared to the waitlist control. Also, the participants in the waitlist control began to get worse. This study showcases that brief interventions for a population with a risk factor (anxiety sensitivity) are effective.

The efficacy of a school-based intervention for social anxiety disorder was examined in a randomized wait-list control trial of 35 adolescents (Masia-Warner, Klein, Dent, 2005). Participants were drawn from 1,521 adolescents of grades 9 through 11 in New York City. They were screened for social anxiety disorder and classroom teachers were asked to nominate up to five students in their class who appeared shy. The nominated students and 
students who scored in the top $15 \%$ on self-rating instruments were selected for further screening. Parents of these adolescents were called and interviewed over the phone and adolescents whom had impairment in functioning were invited to participate in a diagnostic evaluation. Out of the 80 that were interviewed 42 met study criteria. Students were randomly assigned to either SASS (Skills for Social and Academic Success) $(n=21)$ or wait-list control condtion $(n=21)$. The SASS intervention consisted of 12 weekly group school sessions, two brief individual meetings and two group booster sessions. Additionally, four weekend social events which provided "real world exposures and opportunities for skills generalization were conducted. Parents attended two group meetings at school consisting of psychoeducation. All groups were led by psychologists. Participants were evaluated at the end of treatment and 9 months later. Adolescents in the intervention group had significantly greater reduction than the control group in social anxiety and avoidance as well as significantly improved overall functioning. In addition, $67 \%$ of treated subjects compared to $6 \%$ of wait-list control no longer met criteria for social anxiety disorder following treatment.

Masia-Warner, Fisher, Shrout et al (2007) conducted another study similar to the one above but this time compared it to a credible alternate treatment: Educational Supportive Group Function (ESGF). Participants (1789) from grades 9 through 11 were recruited. Out of these 1593 completed and returned screening questionnaires and teachers were asked to nominate shy students. Finally, 36 subjects agreed to participate. Nineteen adolescents were randomized to the SASS (Skills for Social and Academic Success) described above and 17 to the attention control group (ESGF) led by psychologists. The ESGF was designed to be identical to SASS in amount of professional attention and format, however, it omits any therapeutic elements considered specific to reversing social anxiety disorder but includes instructions on relaxation training. The study demonstrated significant reductions in social anxiety for SASS compared to the control group. Parent reports of their children's anxiety did not discriminate between groups. In the SASS group 59\% compared to $0 \%$ in the control group no longer met criteria for social anxiety disorder. At 6-month follow-up, the gains from SASS were maintained.

\section{Conclusion}

In this review, universal prevention strategies are discussed with the beneficial effects of these programs on minimizing risk factors and enhancing protective factors in children. Given the high prevalence rates of childhood anxiety disorders, the distress and impairment associated with them and the high costs of treatment, preventive strategies implemented in the school setting seem to be the most sensible approach. Although anxiety disorders are amongst the most treatable psychiatric disorders, many children fail to receive treatment. Utilizing universal prevention strategies target the greatest number of children in a cost effective manner without stigmatizing or labeling them. By teaching coping skills to students, their anxiety is reduced. These effects have proven to be durable over the course of a few years.

The FRIENDS program (Barrett et al, 2004, 2005) has shown promise as a school based program to decrease anxiety and is being implemented in many different countries. Implementation of the program should be done in a way that fidelity is maintained but the program is still valid within the context of its implementation. It is important that outcome research is done post implementation to study effectiveness of the program and the long term gains. 
Prevention and treatment exist on a spectrum and both are required to reduce the distress and impairment associated with anxiety disorders in children. Historically, however, most public investments have been made in treatment services (Waddell et al, 2004) whereas prevention efforts are often neglected. In the future, the availability of a balance between both prevention and treatment services would be ideal. Both risk and protective factors should be targeted by prevention programs to be more effective.

\section{References}

American Psychiatric Association. (2000). Diagnostic and statistical manual of mental disorder ( $4^{\text {th }}$ ed., text revision). Washington, DC: American Psychiatric Association.

Andrews, G., \& Wilkinson, D. D. (2002). Preventing depression: The prevention of mental issorders in young people. Medical Journal of Australia, 177, S97-S100.

Balle, M. \& Tortella-Feliu, M. (2010). Efficacy of a brief school-based program for selective prevention of childhood anxiety. Anxiety, Stress \& Coping, 23:1, 71.

Barrett, P.M., Dadds, M.R., \& Rapee, R. (1996). Family treatment of childhood anxiety: A controlled trial. Journal of Consulting and Clinical Psychology, 64, 333-342.

Barrett, P. M. (2004). Friends for Life! For children. Participant workbook and leader's Manual. Brisbane, Australia: Australian Academic Press.

Barrett, P. M. (2005). Friends for Life! For youth. Participant workbook and leader's manual. Brisbane, Australia: Australian Academic Press.

Barrett, P. M., \& Turner, C. M. (2000). Childhood anxiety in ethnic families: Current status and future directions. Behavior Change, 17, 113-123.

Barrett, P. M., \& Turner, C. M. (2001). Prevention of anxiety symptoms in primary school children: Preliminary results from a universal school-based trial. British Journal of Clinical Psychology, 40, 399-410.

Barrett, P. M., Farrell, L. J., Ollendick, T. H., \& Dadds, M. (2006). Long term outcomes of an Australian universal prevention trial of anxiety and depression symptoms in children and youth: An evaluation of the FRIENDS Program. Journal of Clinical Child and Adolescent Psychology, 35, 403-411.

Beardslee W., Chien, P., Bell, C., (2011). Prevention of mental disorders, substance abuse and problem behaviors: A Developmental Perspective, Psychiatric News,

Beidel, D. C., \& Turner, S. M. (1998). Clinical presentation of social phobia in children and adolescents. In D. C. Beidel, \& S. M. Turner (Eds.), Shy children, phobic adults: Nature and treatment of social phobia (pp. 33057) Washington DC; American Psychological Association, p. 6.

Beiderman, J., Rosenbaum, J.F., Bolduc-Murphy, e. A., Faraone, S. V., Chaloff, J., Hirshfeld, D.R., \& Kagan, J. (1993). A 3-year follow-up of children with and without behavioral inhibition. Journal of the American Academy of Child and Adolescent Psychiatry, 32, 814-821.

Children's Mental Health Ontario Pre-Budget Submission 2010 [On-line]. Available: http://www.kidsmentalhealth.ca.

Compton, S. N., March, J. S., Brent, D., Albano, A. M., Weersing, V. R. \& Curry, J. (2004). Cognitive-behavioral psychotherapy for anxiety and depressive disorders in children and adolescents: An evidence-based medicine review. Journal of the American Academy of Child nd Adolescent Psychiatry, 43, 930-959. 
Costello, E. J., Angold, A., \& Burns, B. J. (1996). The Great Smoky Mountains study of youth: Goals, design, methods, and the prevalence of DSM-III-R disorders. Archives of General Psychiatry, 53, 1129-1136.

Dadds, M. R., Spence, S., Holland, D. E., Barrett, P. M., \& Laurens, K. R. (1997). Prevention and early intervention for anxiety disorders: A controlled trial. Journal of Consulting and Clinical Psychology, 65, 627-635.

Dadds, M. R., Holland, D. E., Laurens, K, Mullins, M., Barrett, P. M. Spence, S. H. (1999). Early ntervention and Prevention of Anxiety Disorders in Children: Results at 2year Follow-up. Journal of Consulting and Clinical Psychology, 67:1,145-150.

DiLalla, L. F., Kagan, J., \& Reznick, J. S. (1994). Genetic etiology of behavioral inhibition among 2-year-old children. Infant Behavior and Development, 17, 412-415.

Dollinger, S. J., O'Donnell, J. P., \& Staley, A. A. (1984). Lightening-strike disaster: Effects on children's fears and worries. Journal of Consulting and Clinical Psychology, 52, 1028-1038.

Donovan, C.L., \& Spence, S. H. (2000). Prvention of childhood anxiety disorders. Clinical Psychology Review, 20, 509-531.

Dubow, E. F., Schmidt, D., McBride, J., Edwards, S., \& Merk, F. L. (1993). Teaching children to cope with stressful experiences: Implementation and evaluation of a primary prevention program. Journal of Clinical Child Psychology, 22, 428-440.

Erickson, M. F., Sroufe, L. A., \& Egeland, B. (1985). The relationship between quality of attachment and behavior problems in preschool and a high-risk sample. Monographs of the Society for Research in Child Development, 50, 147-166.

Farrell, L. J. \& Barrett, P.M. (2007). Prevention of Childhood Emotional Disorders: Reducing the Burden of Suffering Associated with Anxiety and Depression. Child and Adolescent Mental Health, 12; 2, 58-65.

Garland, J., \& Clark, S. (2000). Taming Worry Dragons: A manual for children, parents and other Coaches (Rev.). Vancouver, Canada: British Columbia Children's Hospital.

Goodman, R., ford, T., Richards, H., Gatward, R., \& Meltzer, H. (2000). The development and well-being assessment: Description and initial validation of an integrated asessessment of child and adolescent psychopathology. Journal of Child Psychiatry, 41, 645-655.

Greenberg, M. T., Domitrovich, C., Bumbarger, B. (1999). Preventing mental disorders in school age children: A review of the effectiveness of prevention programs (US Department of Health and Human Services, Centre for Mental Health Services report). [On-line]. Available: http:/www.psu.edu/dept/prevention/CMHS.html.

Haines, A. A., (1992). Comparison of Cognitive-Behavioral Stress Management Techniques with Adolescent Boys. Journal of Counseling \& Development, 70, 600- 605.

Hawkins, D. J., \& Catalano, R. F. (1992). Communities that care: Action for drug abuse Prevention. San Francisco, CA; Jossey-Bass.

Hunt, C., Andrews, G., Crino, R., Erskine, A., Sakashita, C. (2009). Randomized controlled trial of an Early Intervention programme for adolescent Anxiety Disorders. Australian and New Zealand Journal of Psychiatry, 2009: 43:300-304.

In-Albon, T., \& Schneider, S. (2007). Psychotherapy of childhood anxiety disorders: A metaanalysis. Psychotherapy and Psychosomatics, 76, 15-24.

Jessor, R. (1991). Risk behavior in adolescence: A psychosocial framework for understanding and action. Journal of Adolescent Health Special Issue: Adolescents at Risk, 12, 597-605. 
Jessor, R., Van Den Bos, J., Vanderryn, J., Costa, F. M., \&Turbin, M. S. (1995). Protective factors in adolescent problem behavior: Moderator effects and developmental change. Developmental Psychology, 31, 923-933.

Kagan, J., Reznick, J. S., \& Gibbons, J. (1989). Inhibited and uninhibited types of children. Child Development, 60, 838-845.

Kagan, J., \& Snidman, N. (1991). Infant predictors of inhibited and uninhibited profiles. Psychological Science, 2, 40-43.

Kagan, J. (1997). Temperament and the reactions to unfamiliarity. Child Development, 68, 139-143.

Kendall, P.C. (1994). Treating anxiety disorders in youth; Results of a randomized clinical trial. Journal of Consulting and Clinical Psychology, 62, 100-101.

Kennedy, S. J., Rapee, R. M., Edwards, S. (2009). A Selective Intervention Program of Inhibited Preschool-Aged Children of Parents with an Anxiety Disorder: Effects on Current Anxiety Disorders and Temperament. Journal of Am Acad of Child and Adol. Psychiatry, 48:6, 602-609.

Kessler, R. C., Berglund, P., Demler, O., Jin, R., Merikangas, K., \& Walters, E. (2005). Lifetime prevalence and age-of-onset distributions of DSM-IV disorders in the National Comorbidity Survey Replication. Archives of General Psychiatry, 62, 593-602.

Krohne, H.W., \& Hock, M. (1991). Relationships between restrictive mother-child interactions and anxiety of the child, Anxiety Research, 4, 109-124.

Last, C. G., Perrin, S., Hersen, M., \& Kazdin, A. E. (1996). A prospective study of childhood anxiety disorders. Journal of the American Academy of Child and Adolescent Psychiatry, 35, 1502-1510.

Lefeuve, C.E., Litten, R. Z., Randall, C. L., Moak, D. H., Salloum, I. M., \& Green, A I. (2004). Pharmacological treatment of alcohol abuse/dependence with psychiatric comorbidity. Alcoholism, Clinical and Experimental Research, 28, 302-312.

LaFreniere, P.J., \& Capuano, F. (1997). Preventive intervention as a means of clarifying direction of effects in socialization: Anxious-withdrawn preschoolers case. Development and Psychopathology, 9, 551-564.

Lewinsohn, P. M., \& Clarke, G. N. (1999). Psychosocial treatment for adolescent depression. Clinical Psychology Review, 19, 329-342.

Lewis, M., Feiring, C., McGafey, C., \& Jaskir, J. (1984). Predicting psychopathology in sixyear- olds from early social relations. Child Development, 55, 123-136.

Leen-Feldner, E. W., Reardon, L.E., \& Zvolensky, M.J. (2007). Pubertal status and emotional reactivity to a voluntary hyperventilation challenge predicting panic symptoms and somatic complaints: A laboratory-based multi-informant test. Behavior Modification, 21, 8-31.

Lock, S., \& Barrett, P. M. (2003). A longitudinal study of developmental differences in Universal preventative ntervention for child anxiety. Behavior Change, 20, 183-99.

Lowry-Webster, H. M., Barrett, P. M., Dadds, M. R. (2001). A Universal Prevention Trial of Anxiety and Depressive Symptomatology in Childhood: Preliminary data from an Australian Study. Behaviour Change, 18:1, 36-50.

Lowry-Webster, H. M., Barrett, P. M., \& Lock, S. (2003). A universal prevention trial of anxiety symptomatology during childhood: Results at 1-year follow-up. Behavior Change, 20, 25-43. 
Masia-Warner, C, Klein, R. G., Dent, H. C., Fisher, P. H. Alvir, J, Albano, A. M., Guardino, M. (2005). School-based interventions for adolescents with social anxiety disorder: Results of a controlled study, Journal of Abnormal Child Psychology, 33:6, 707-722.

Masia-Warner, C, Fisher, P. H., Shrout, P. E., Rathor, S., Klein, R. G.. (2007). Treating Adolesents with social anxiety disorder in school: an attention control trial. Journal of Child Psychology and Psychiatry, 48:7, 676-686.

Miller, L. D., Short, C, Garland, E. J. Clark, S., (2010). The ABCs of CBT (Cognitive Behavior Therapy): Evidence-Based Approaches to Child Anxiety in Public School Settings, Journal of Counseling \& Development, 88, 432-439.

Mrazek, P. J., \& Haggerty, R. J. (1994). Reducing risks for mental disorders. Washington, DC: National Academy Press.

Muris, P., Merckelbach, H., Mayer, B., \& Prins, E. (2000). How serious are common childhood fears? Behaviour Research and Therapy, 38, 217-228.

National Institutes of Health \& Substance Abuse and Mental Health Services Administration (1999). Mental health and mental disorders \{pp. 18(1)-18(32)\}. In National Institutes of Mental Health (Ed.) Healthy People 2010: Conference Edition. Washington, DC: National Institutes of Health.

Otto, M. W., Leyro, T. M., Christian, K., Deveney, C. M., Reese, H., Pollack, M. Hl, et al. (2007). Prediction of "fear" acquisition in health control participants in a de novo fear-conditioning paradigm. Behavior Modification, 31, 32-51.

Offord, D. R., Chmura Kraemer, H., Kazdin, A. E., Jensen, P. S., \& Harrington, R. 1998). Lowering the burden of suffering from child psychiatric disorder: Trade-offs among clinical, targeted, and universal interventions. Journal of American Academy of Child and Adolescent Psychiatry, 37, 686-694.

Pine, D. S., Cohen, P., Gurley, D., Brook, J., \& Ma, Y. (1998). The risk for early adulthood anxiety and depressive disorders in adolescents with anxiety and depressive disorders. Archives of General Psychiatry, 55, 56-64.

Quinton, D., Pickles, A., Maughan, B., \& Rutter, M. (1993). Partners, peers, and pathways: Assortative pairing and continuities in conduct disorder. Development and Psychopathology Special Issue: Milestones in the development of resilience, 5, 763-783.

Rapee , R. M., \& Spence, S. H. (2004). The etiology of social phobia: Empirical evidence and an initial model. Clinical Psychology Review, 24, 737-767.

Rapee, R. M., Kennedy, S., Ingram, M., Edwards, S., and Sweeney, L. (2005). Prevention and Early Intervention of Anxiety Disorders in Inhibited Preschool Children. Journal of Consulting and Clinical Psychology, 73:3, 488-497.

Rapee, R. M., Kennedy, S., Ingram, M, Edwards, S., and Sweeney, L. (2010). Altering the Trajectory of Anxiety in At-Risk Young Children. Amerian Journal of Psychiatry, 167:12, 1518- 1525.

Robertson, E. B., David, S. L., \& Rao, S. A., (2003). Preventing drug use among children and adolescents: A research-based guide for parents, educators, and community leaders, second edition [NIH Publication No, 04-421 (A)]. Retrieved from the National Institute on Drug Abuse website: http://www.drugabuse.gov/prevention/prevopen.html

Rosenbaum, J.F., Biederman, J., Gerten, M., Hirshfeld, D. R., Meminger, S. R., Herman, J. B., Kagan, J., Reznick, J.S. \& Snidman, N. (1988). Behavioral inhibition in children of parents with panic disorder and agoraphobia: A controlled study. Archives of General Psychiatry, 45, 463-470. 
Rosenbaum, J.F., Biederman, J., Bolduc-Murphy, E. A., Faraone, S.V., Chaloff, J., Hirshfeld, D. R. \& Kagan, J. (1993). Behavioral inhibition in childhood: A risk factor for anxiety disorders. Harvard Review of Psychiatry, 1 (1), 2-16.

Schatzberg, A. F., Samson, J. A., \& Rothschild, A. J. (1998). McLean Hospital Depression Facility: Early-onset phobic disorders and adult onset major depression. British Journal of Psychiatry, 173, 29-34.

Spence, S. H. (2001). Prevention strategies. In m. W. Vasey \& M. R. Dadds (Eds.). The developmental psychopathology of anxiety, 101-132. New York: Oxford University Press.

Sroufe, L.A., Egeland, B., \& Kreutzer, T. (1990). The fate of early experience following developmental change: Longitudinal approaches to individual adaptation in childhood. Child Development, 61, 1363-1373.

Stallard, P, Simpson, N. Anderson, S. Hibbert, S., Osborn C. (2007). The FRIENDS emotional health programme: Initial findings from a school based project. Child and Adolescent Mental Health, 12:1, 32-37.

Thapar, A., \& McGuffin, P. (1995). Are anxiety symptoms in childhood heritable? Journal of Child Psychology and Psychiatry, 36, 439-447.

Turner, S. M., Beidel, D. C., \& Costello, A. (1987). Psychopathology in the offspring of anxiety disorders patients. Journal of Consulting and Clinical Psychology, 55, 229-235.

Turner, S. M., Beidel, D. C., \& Wolff, P.L. (1996). Is behavioral inhibition related to the anxiety disorders? Clinical Psychology Review, 16, 157-172.

Waddell, C., Godderis, R., Hua, J., McEwan, K., Wong, W. (2004) Preventing and treating Anxiety Disorders in Children and Youth: A Research report prepared for the British Columbia Ministry f Children and Family Development. Children's Mental Health Policy Research Program, University of BC Walker, J. R., Ediger, J., Joyce, B., Furer, P., Vincent, N., \& Kjernisted, K. D. (2001). A survey of preference for pharmacological and psychological treatment for anxiety problems in an anxiety disorders clinic. Poster session presented at the Anxiety Disorders Association of America, $21^{\text {st }}$ National Conference, Atlanta, GA.

Warren, S. L., Huston, L., Egeland, B., \& Sroufe, L. A. (1997). Child and adolescent anxiety disorder and early attachment. Journal of the American Academy of Child and Adolescent Psychiatry, 36, 637-644.

Weissman, M. M., Leckman, J.F., Merikangas, K. R., Gammon, g. D., \& Prusoff, B. (1984). Depression and anxiety disorders in parents and children: Results from the Yale Family Study. Archives of General Psychiatry, 41, 845-852.

Weist, M. D. (1999). Challenges and opportunities in expanded school mental health. Clinical Psychology Review, 19(2), 131-135.

Weisz, J. R., Thurber, C. a., Sweeney L., Proffitt V. D. \& LeGagnoux G. L. (1997). Brief treatment of mild-to-moderate child depression using primary and secondary control enhancement training. Journal of Consulting and Clinical psychology, 65, 703-707.

World Health Organization (2004). Prevention of Mental Disorders: Effective interventions and policy options. Geneva. Retrieved October 1, 2004, from http://www.who.int/entity/mental/health/evidence/en/prevention_of_mental_ disorders.sr.pdf 


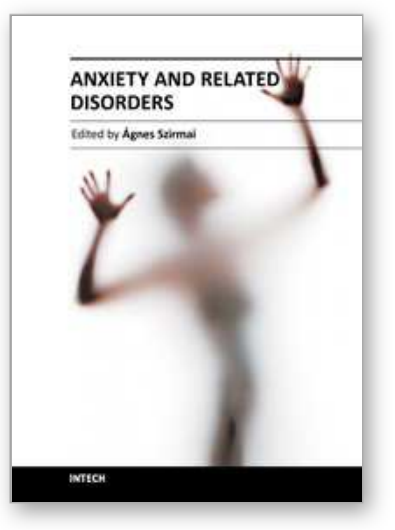

\author{
Anxiety and Related Disorders \\ Edited by Dr. Ãgnes Szirmai
}

ISBN 978-953-307-254-8

Hard cover, 292 pages

Publisher InTech

Published online 29, August, 2011

Published in print edition August, 2011

Anxiety disorders are one of the most common psychiatric disorders worldwide and many aspects of anxiety can be observed. Anxious patients often consult primary care physicians for their treatment, but in most cases they do not accept the diagnosis of anxiety disorder. Anxiety is a symptom that could be seen in many organic disorders and can accompany almost any psychiatric disorder. Anxiety disorders are frequent and are associated with significant distress and dysfunction. Stigmatization is an important factor in insufficient diagnosis. The problems of anxiety cover all fields of life. This book intends to describe the epidemiological aspects and the main co-morbidities and consecutive diseases of the anxiety disorders.

\title{
How to reference
}

In order to correctly reference this scholarly work, feel free to copy and paste the following:

Sarosh Khalid-Khan (2011). Prevention of Childhood Anxiety Disorders, Anxiety and Related Disorders, Dr. Ãgnes Szirmai (Ed.), ISBN: 978-953-307-254-8, InTech, Available from:

http://www.intechopen.com/books/anxiety-and-related-disorders/prevention-of-childhood-anxiety-disorders

\section{INTECH}

open science | open minds

\section{InTech Europe}

University Campus STeP Ri

Slavka Krautzeka 83/A

51000 Rijeka, Croatia

Phone: +385 (51) 770447

Fax: +385 (51) 686166

www.intechopen.com

\section{InTech China}

Unit 405, Office Block, Hotel Equatorial Shanghai

No.65, Yan An Road (West), Shanghai, 200040, China

中国上海市延安西路65号上海国际贵都大饭店办公楼 405 单元

Phone: +86-21-62489820

Fax: +86-21-62489821 
(C) 2011 The Author(s). Licensee IntechOpen. This chapter is distributed under the terms of the Creative Commons Attribution-NonCommercialShareAlike-3.0 License, which permits use, distribution and reproduction for non-commercial purposes, provided the original is properly cited and derivative works building on this content are distributed under the same license. 